\title{
Theoretical Basis in Regression Model Based Selection of the Most Cost Effective Parameters of Hard Rock Surface Mining
}

\author{
Antipas T. S. Massawe, Karim R. Baruti, Paul S. M. Gongo \\ Department of Chemical \& Mining Engineering, College of Engineering \& Technology, \\ University of Dar es Salaam, Dar Es Salaam, Tanzania \\ E-mail:massaweantipas@hotmail.com \\ Received October 2, 2010; revised November 22, 2010; accepted December 13, 2010
}

\begin{abstract}
What determines selection of the most cost effective parameters of hard rock surface mining is consideration of all alternative variants of mine design and the conflicting effect of their parameters on cost. Consideration could be realized based on the mathematical model of the cumulative influence of rockmass and mine design variables on the overall cost per ton of the hard rock drilled, blasted, hauled and primary crushed. Available works on the topic mostly dwelt on four processes of hard rock surface mining separately. This paper dwells on the theoretical part of a research proposed to enhance effectiveness in the selection of the parameters of hard rock surface mining design based on the regression model of overall cost per tonne of the rock mined fit on the determinant variations of rockmass and mine design. The regression model could be developed based on the statistical data generated by many of the hard rock surface mines operating in variable conditions of rockmass and mine design worldwide. Also, a regression model based general algorithm has been formulated for the development of software and computer aided selection of the most cost effective parameters of hard rock surface mining.
\end{abstract}

Keywords: Parameters of Rockmass, Parameters of Mining Design, Regression Model, Algorithm of Selection

\section{Introduction}

Hard rock surface mining produces most of the metal ores and construction rock aggregates mined from shallow deposits using explosives in rock fragmentation and trucks for the mine haulage. It is a mining system of interdependently functioning parameters of mining design in rock drilling, blasting, haulage and primary crushing $[1,2]$. Most of these parameters have several variants which are applicable and most of them exhibiting variable levels of conflicting effect on the costs per tonne of the rock mined in drilling, blasting, hauling and primary crushing in any class of rockmass parameters. The desired effectiveness of such a system could only be achieved from the selection of mining design parameters which are most fit in given class of rockmass parameters and well marched in accordance to their functional and/ production capabilities to deliver the minimum overall cost per tonne of the rock mined.
The most cost effective parameters of the system could be established based on the mathematical model of the cumulative influence of rockmass and mining design variations on the overall cost per ton of the rock mined in drilling, blasting, hauling and primary crushing.

Most of the models available for the selection of hard rock surface mining parameters dwell on the subprocesses of drilling, blasting, hauling and primary crushing separately and don't consider all alternative variants and the cumulative effect of all determinant variables on effectiveness [3-13]. Desired model could be developed as the regression model of overall cost per ton of rock mined in drilling, blasting, hauling and primary crushing fit on the rockmass and mining design variations of hard rock surface mining using the huge data generated by many of the hard rock surface mines operating in variable conditions of rockmass and mine design worldwide. A general algorithm could be formulated based on the regression model of overall cost for development of the 
software required for computer aided comparison of variants and selection of the most cost effective parameters of hard rock surface mining.

Therefore, aim in this paper is to formulate the theoretical basis for the development of a regression model of overall cost per tonne of the rock mined fit on the rockmass and mining design variations of hard rock surface mining worldwide and the general algorithm for development of software required for the computer aided comparison of variants and selection of the most cost effective parameters of drilling, blasting, hauling and primary crushing in any rockmass conditions of hard rock surface mining.

\section{Assessment of Hard Rock Surface Mining Cost}

\subsection{Formulation of Regression Model}

The cost of hard rock surface mining could be stated as the overall cost per ton of the rock mined and assessed based on the regression model of the overall cost per tonne of rock mined fit on the rockmass and mining design variations of hard rock surface mining in drilling, blasting, haulage and primary crushing illustrated on (1).

$$
C_{T}(\vec{B} ; \vec{X})=\sum_{i s=1}^{i s=4} F_{i s}(\vec{B} ; \vec{X})
$$

where: $\vec{B}$-Vector of the unregulated rockmass variables $\left(\vec{B}=B_{1}, B_{2}, \cdots, B_{k}, \cdots, B_{n}\right) ; \vec{X}-$

Vector of the regulated mine design variables $\left(\vec{X}=X_{1}, X_{2}, \cdots, X_{l}, \cdots, X_{t}\right) ; C_{T}(\vec{B} ; \vec{X})$-The overall cost per ton of the rock mined in given vectors of rockmass and mining design variables;

$F_{1}(\vec{B} ; \vec{X}) ; F_{2}(\vec{B} ; \vec{X}) ; F_{3}(\vec{B} ; \vec{X})$ and

$F_{4}(\vec{B} ; \vec{X})$-Sub costs per ton of the rock mined in given vectors of rockmass and mining design variables in drilling, blasting, hauling and primary crushing respectively.

\subsection{The Determinant Variables}

The cost effect of hard rock surface mining is mostly affected by the parameters of rockmass and mining design. The most important of these parameters are listed on Table 1.

The effect of mine design variables such as hole diameter, powder factor, production capacity or size of equipment on the costs per ton of the rock mined in drilling, blasting, hauling and primary crushing in any class of rockmass variables is conflicting as described below:

\subsubsection{Powder Factor}

The intensification of rock fragmentation achievable from increased powder factor is also associated with decreased costs in loading, hauling and primary crushing and increased costs on the increased consumption of explosive and meters to drill [12].

\subsubsection{Hole Diameter}

Increased hole diameter is also associated with decreased costs on the decreased meters to drill and the enhanced performance of explosive and increased costs on loading, hauling and primary crushing of the coarse fragmented rock products [12].

\subsubsection{Size of Equipment}

Increased size of equipment is also associated with decreased labour cost on handling the decreased number of equipment. Also, increased size of loading equipment, haul truck and primary crusher means the possibility of using large diameter holes which are associated with decreased costs on the decreased meters to drill and the enhanced performance of explosive and increased costs on secondary blasting, loading, hauling and primary crushing of the coarse fragmented rock products [12,13]. The increased number of equipment achieved from size reduction could also be associated with the increased or decreased cost resulting from increased or decreased system reliability.

The conflicting effect described above, requires selection of the most cost effective parameters of hard rock surface mining to be carried out based on the regression model of the cumulative influence of the variables of rockmass and mining design on the overall cost per ton of the rock mined in the comparative assessment of variants and selection of the most cost effective variant of hard rock surface mining in any class of rockmass parameters.

\subsection{Development of Regression Model}

The regression model of the cumulative effect of rockmass and mining design variables on the overall cost per ton of the rock mined given on (1) could be developed from the huge statistical data of costs in drilling $F_{1 m}$ blasting $F_{2 m}$, haulage $F_{3 m}$ and primary $F_{4 m}$ vs. the parameters of rockmass $\vec{b}_{m}$ and mining design $\vec{x}_{m}$ generated from $m=1, m \max$ worldwide operating hard rock surface mines. Data analysis in the generation of regression model could be carried out using one of the suitable among the available standard statistical correlation-Regression analysis software. 
Table 1. The determinant variables of cost in hard rock surface mining.

\begin{tabular}{|c|c|}
\hline $\begin{array}{l}\text { Name of Vector } \\
\text { Rockmass } \vec{B}\end{array}$ & $\begin{array}{l}\text { Alterative Variables } \\
B_{1} \text {-Compressive rock strength, } \mathrm{M}_{\mathrm{pa}} ; B_{2} \text {-Tensile rock strength, } \mathrm{M}_{\mathrm{pa}} ; B_{3} \text {-Rock bending } \\
\text { (shear) strength, } \mathrm{M}_{\mathrm{pa}} ; B_{4} \text {-Rock density, } \mathrm{T} / \mathrm{m}^{3} ; B_{5} \text {-Rock jointing. }\end{array}$ \\
\hline Mining design $\vec{X}$ & 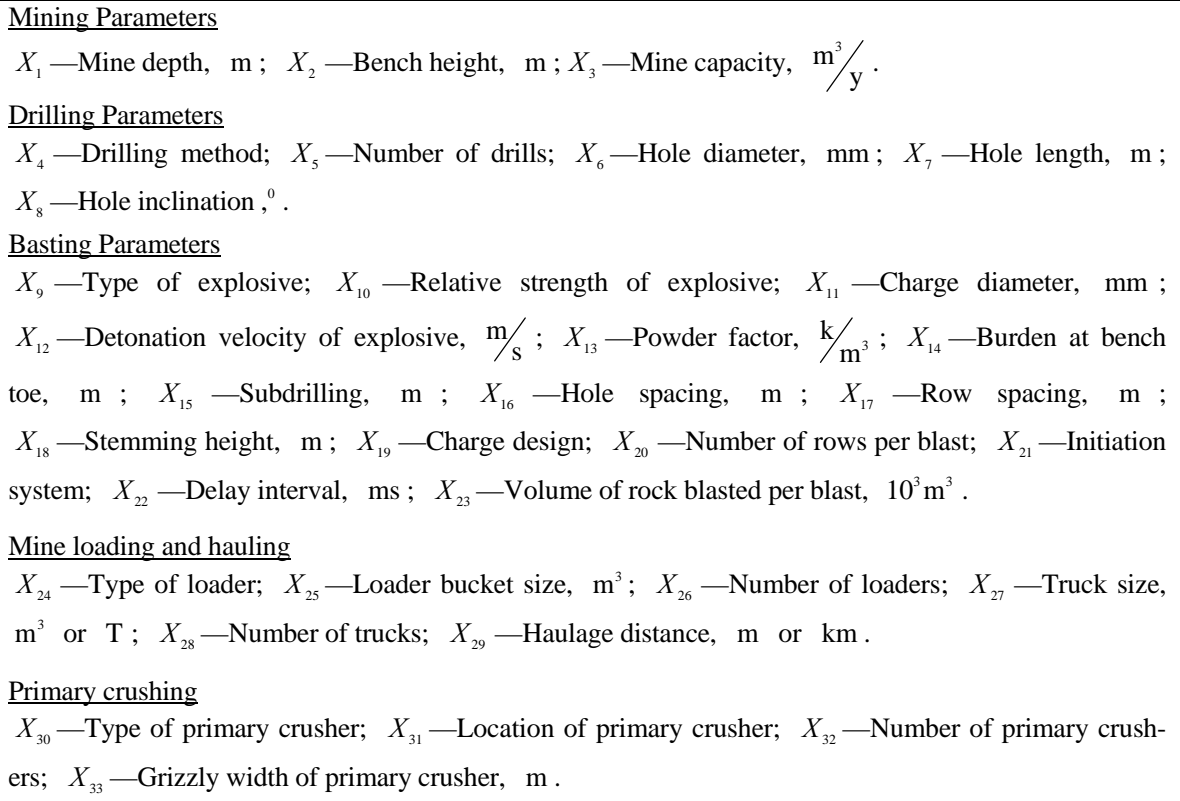 \\
\hline
\end{tabular}

\section{Selection of the Parameters of Mining Design}

Selection of the parameters of a hard rock surface mining design is based on the regression model of overall cost which could be developed as described above, the parameters of rockmass design of the mine and the alternative parameters of mining design for the mine.

\subsection{Determinant Parameters}

\subsubsection{Rockmass Parameters}

Most often, the parameters of rockmass design $\vec{b}_{m}$ which affect the overall cost of hard rock surface mining are different from one mine to the other. Therefore, the parameters of rockmass design $\vec{b}_{g} \equiv b_{g j}(j=1,6)$ are the first inputs in the regression model of cost based selection of the parameters of a hard rock surface mining design.

\subsubsection{Mine Design Parameters}

Most of the parameters of mining design $\vec{x}_{m}$ have several alternative parameters $\vec{x}_{m}=\vec{x}_{m i j}\left(i=33 ; j=1, x_{m n x_{i}}\right)$ which are applicable (with different levels of effectiveness) for hard rock surface mining in any class of rockmass design and determined by site geometry, mine size and environmental and organizational conditions of the mine. All the alternative parameters of mining design in any class of rockmass design are the second inputs in the regression model of cost based selection of the parameters of hard rock surface mining design.

\subsection{Alternative Variants of Mine Design}

Alternative variant of a mining design in given class of rockmass design $\vec{b}_{m}$ is any combination of one alternative parameter from each of the $X_{m i}(i=1,33)$ variables of mining design. The maximum number of alternative variants of mining design $n_{m m x}$ which could be obtained from all different combinations of the alternative parameters from all variables of mining design is the third input in the regression model of cost based selection of the parameters hard rock surface mining design and established using (2). Not all alternative variants are operational. The number of operational alternative variants of a mining design $n_{m n \vec{x}}$ which is obtained from all operational combinations of the alternative parameters of mining design in given class of rockmass design is calculated using (3).

$$
\begin{aligned}
n_{m m x} & =\prod_{1}^{33} n x_{m i} \\
n_{m n \bar{x}} & =n_{m m x}-n_{-m n \bar{x}}
\end{aligned}
$$


where: $n x_{m i}$-Number of the alternative parameters of mining design for the $i^{\text {th }}$ variable of mining design in given class of rockmass design; $n_{-m n \vec{x}}$-Number of non-operational alternative variants of mining design which is obtained from all non-operational combinations of the alternative parameters of mining design. A matrix of the non-operational alternative variants of mining design is the fourth input in the regression model of cost based selection of the parameters of hard rock surface mining design.

\subsection{Mathematical Formulation of Problem}

The mathematical formulation of problem in the regression model based comparison of the alternative variants of hard rock surface mining $n_{m n \dot{x}}$ and selection of the most cost effective parameters of mining design $\vec{x}_{\text {om }}=x_{\text {omi }}(i=1,33)$ corresponding to the variant of least cost per tonne of the rock mined $C_{\text {Tmmin }}$ in given parameters of rockmass design $\vec{b}_{m}=b_{m j}(j=1,6)$ is described on (4) and (5)

$$
\begin{gathered}
\vec{x}_{o m} \cong C_{T m m i n} \\
C_{T m i n}=\min \sum_{i s=1}^{i s=n s} F_{i s}\left(\vec{b}_{m} ; \vec{x}_{m k}\right)
\end{gathered}
$$

where: $F_{i s}$-Cost per tonne of the rock mined per each of the $i s=1,(n s=4)$ sub-systems of drilling, blasting, hauling and primary crushing in hard rock surface mining; $\vec{x}_{m k}\left(k=1, n_{m n \vec{x}}\right)$-Possible variants of mining design in given class of rockmass design

$\vec{b}_{m}=b_{m j}(j=1,6)$.

\subsection{The General Algorithm of Analysis and Selection}

The algorithm of analysis and selection of the most cost effective parameters of hard rock surface mining design $\vec{x}_{\text {om }}=x_{\text {omi }}(i=1,33)$ in given parameters of rockmass design $\vec{b}_{m}=b_{m j}(j=1,6)$ is developed based on the developed regression model of overall cost per ton of rock mined in drilling, blasting, hauling and primary crushing fit on the rockmass and mining design variations of hard rock surface mining described on (1); matrix of alternative parameters of mining design

$$
\vec{x}_{m k}=x_{m i k}\left(i=1,33 ; k=1, n_{m m \vec{x}}\right) \text {, in given parame- }
$$
ters of rockmass design; matrix of the non-operational variants of the alternative variants of mining design and the mathematical formulation of problem in the analysis and selection of the most cost effective parame- ters of hard rock surface mining described on (4) and (5).

The algorithm operates in accordance to the following points:

1) Formation of data base.

2) First variant of hard rock surface mining design is formed: $\vec{x}_{m i}$.

3) Calculation of the overall cost per ton of the rock mined in drilling, blasting, hauling and primary crushing using formula described on (1).

4) Execution of procedures in the selection of variant and parameters of mining design corresponding to the minimum overall cost per tonne of the rock mined.

5) The next variant of the alternative variants of hard rock surface mining design is formed. Procedures of assessment, comparison and selection of the most cost effective variant and parameters of hard rock surface mining are repeated. Computation ends when the operational alternative variants of hard rock surface mining design are all covered in the selection process.

The block scheme of algorithm for the comparison of the operational alternative variants and generation of the most cost effective variant and parameters of hard rock surface mining design in given class of rockmass design is illustrated on appendix.

\section{Conclusions and Recommendations}

The main parameters of rockmass and mining design that affect the overall cost per tonne of the rock drilled, blasted, hauled and primary crushed have been identified, enabling the formulation of theory for the development of a mathematical model of their cumulative impact on the cost effectiveness of hard rock surface mining. Development of the regression model of overall cost fit on the rockmass and mining design variations of hard rock surface mining worldwide has been described, enabling the planning of data collection and development of the model. The regression model of overall cost based general algorithm has been formulated, enabling the development of software for the computer aided analysis and selection of the most cost effective parameters of hard rock surface mining in any class of rockmass parameters.

Realization of the theory described above should always enable implementation of the most progressive systems approach methodology in the assessment of all alternative variants and selection of the most cost effective parameters of hard rock surface mining in any class of rockmass parameters.

\section{References}

[1] W. Hustrulid and M. Kuchta, "Open Pit Mine Planning and Design,” Taylor \& Francis, London, 2006. 
[2] B. Kennedy, “Surface Mining,” SME, Colorado, 1990.

[3] T. Afeni, "Optimization of Drilling and Blasting Operations in an Open Pit Mining-The Société des Mines del' Air Experience,” Mining Science and Technology (China), Vol. 19, No. 6, 2009, pp. 736-739. doi:10.1016/S1674-52 64(09) 60134-4

[4] A. Bortolussi, R. Ciccu, S. Forte and B. Grosso, "A Contribution to a Better Design and Control of Surface Blasting,” Balkema, Rotterdam, 2000.

[5] S. Qu, S. Hao, G. Chen, B. Li and G. Bian, "The Blast-Code Model-A Computer-Aided Bench Blast Design and Simulation System," Fragblast, Vol. 6, No. 1, 2002, pp. 85-103. doi:10.1076/frag.6.1.85.8852

[6] A. Mishra, "Design of Surface Blasts-A Computational Approach," Bachelor of Science Thesis, Department of Mining Engineering, National Institute of Technology, 2009.

[7] E. Bozorgrahimi, R. A. Hall and G. H. Blackwell, "Sizing Equipment for Open Pit Mining," A Review of Critical Parameters of Mining Technology, Vol. 112, 2003, pp.
171-179.

[8] R. Franke, "Combined Mining Systems for Open Pit Mines," Bulk Handling in Open Pit Mines \& Quarries, 1986, pp. 177-182.

[9] H. Althof, "Cost Reduction by In-Pit Crushing and Conveying," Handling in Open Pit Mines \& Quarries, 1986, pp. 205-208.

[10] G. Adel, T. Kojovic and D. Thornton, "Mine-to-Mill Optimization of Aggregate Production,” Virginia Polytechnic Institute of State University, Virginia, 2006.

[11] R. Zhang, Y. Zhang, T. X. Ren and B. Denby, “The Selection of Surface Mining Technology Using a Decision Making System,” Balkema, Rotterdam, 1998.

[12] A. T. S. Massawe, "Drilling \& Blasting Part I: Blasting Lecture Notes and Tutorials,” LAP LAMBERT Academic Publishing, Saarbrucken, 2010.

[13] A. T. S. Massawe, "Drilling \& Blasting Part II: Drilling Manual,” LAP LAMBERT Academic Publishing, Saarbrucken, 2010. 


\section{Appendix}

The algorithm of analysis and selection of the most cost effective parameters of hard rock surface mining.

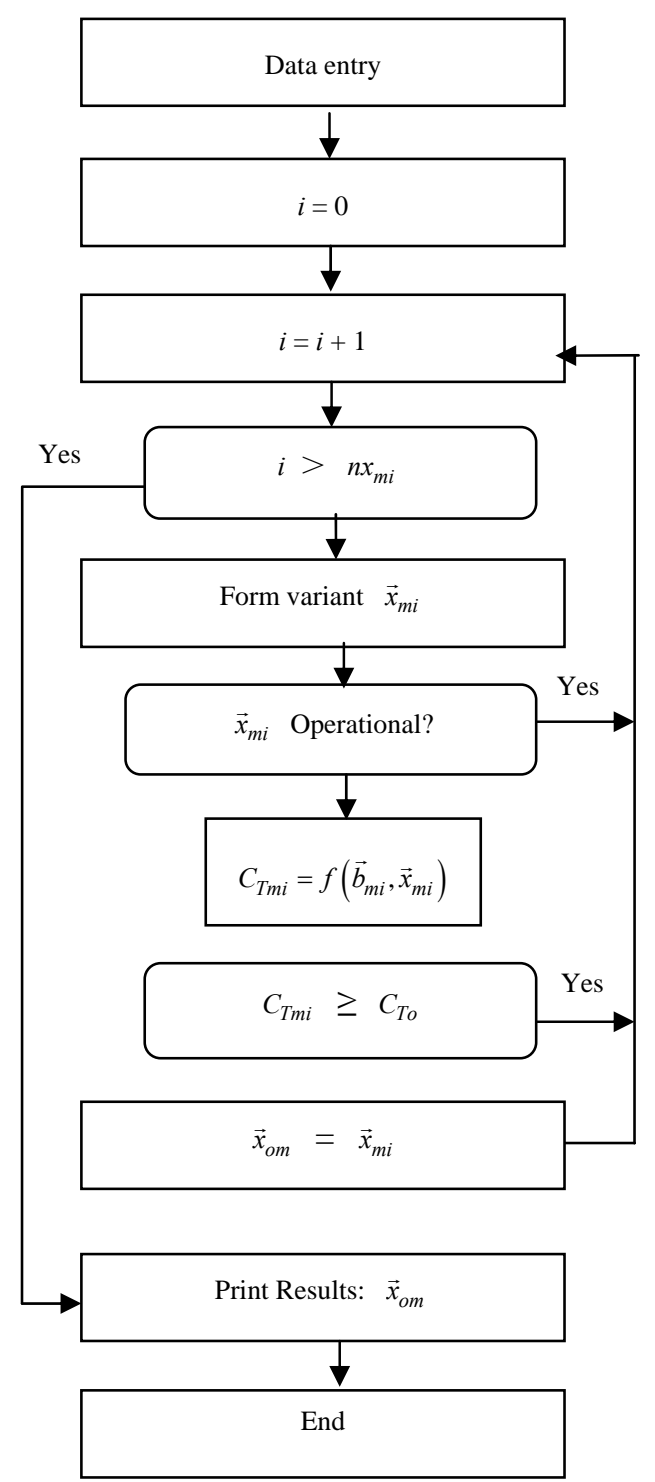

